\title{
FireMapper'T: A Thermal-Imaging Radiometer for Wildfire Research and Operations
}

\author{
Philip J. Riggan \\ USDA Forest Service \\ Pacific Southwest Research Station \\ 4955 Canyon Crest Drive \\ Riverside, CA 92507 \\ 9096801534 \\ pjriggan@attglobal.net \\ James W. Hoffman \\ Space Instruments, Inc. \\ 4403 Manchester Avenue, Suite 203 \\ Encinitas, CA 92024 \\ 7609447001 \\ jhoffsi@aol.com
}

Abstract - Airborne trials have produced the first applications of a new thermal-imaging radiometer, the FireMapper, which is a unique three-channel, calibrated imaging system designed through a Research Joint Venture between the USDA Forest Service and Space Instruments, Inc. FireMapper has been designed to map the progress and intensity of wildland fires but has sufficient sensitivity to be useful in terrain mapping, disaster management, and naturalresource monitoring. FireMapper employs a microbolometer detector array that requires no cryogenic cooling, as do conventional mercury-cadmium-telluride detectors, and thus offers a less complex and less expensive thermal-imaging system. The prototype design employs a filter wheel to provide two narrow-band channels, at wavelengths of 8.1 to $9 \mu \mathrm{m}$ and 11.4 to $12.4 \mu \mathrm{m}$, and a broadband channel from 8.1 to $12.4 \mu \mathrm{m}$. Calibrations of radiance as a function of instrument digital number are stable and highly linear. The 11.4- to $12.4-\mu \mathrm{m}$ channel, which saturates only above $1216^{\circ} \mathrm{C}$, has proven useful in characterizing the very high radiances associated with major flaming fronts. Two levels of onboard blackbody calibration provide real-time correction of offset drift in the detector array and an absolute through-the-lens blackbody calibration upon user demand. The latter corrects for reflections within the instrument and produces a flat-field image of the target scene. Digital time-delay integration may also be selected to improve measurement sensitivity. The onboard user interface provides real-time image viewing and enhancement, instrument setup and control, and real-time data on instrument status. Results show that the FireMapper can successfully characterize flaming front environments and temperatures with the potential for improving tactical fire suppression operations, fire-fighter safety, and our understanding of fire behavior and the environmental impacts of wildland fire.

U.S. Government work not protected by U.S. copyright. IEEE AC paper \#1522.

\section{TABLE OF CONTENTS}

\author{
1. INTRODUCTION \\ 2. THE FIREMAPPER SYSTEM \\ 3. Fire MEASUREMENTS \\ 4. DISCUSSION
}

\section{INTRODUCTION}

There is a fundamental and unmet need in fire science and management today to consistently monitor and understand the behavior of wildland fires at their full scale and as they occur. Fire fronts and spots fires alike may be obscured by smoke and terrain, are dangerous to approach, and are often unpredictable as to location, impact, and rate of spread.

Reliable fire information is needed for tactical fire suppression, to understand and mitigate fire effects in the environment, to evaluate the effectiveness of fuel treatments and justify their use, and for testing and improving performance of operational fire-behavior simulation models. Together with GPS-based asset tracking, remote sensing could improve fire-fighter safety by showing the spatial relation of fire fighters and equipment to the fire, and especially to regions of high fire intensity or activity.

Fire-behavior models, whose results are sometimes relied upon as a proxy for fire observations, have been largely based on laboratory-scale experiments [1] with flame lengths on the order of one meter. Their application to fires with high rates of energy release requires a wide and questionable extrapolation to conditions sometimes producing flame lengths of tens of meters.

Airborne remote sensing at infrared wavelengths has the potential to accurately quantify large-fire properties and behavior, including energy release or intensity, residence time, fuel consumption rate, rate of spread, and soil heating 
[2]. Remote sensing at a high temporal rate can track fireline outbreaks and acceleration and the location and rates of spotting ahead of a fire front. However, infrared imagers and imaging spectrometers currently used for operational fire management and earth remote sensing typically are saturated by - and are incapable of measuring - the very bright infrared light that radiates from large wildland fires. Thus they provide a limited or even distorted view of fire activity (Figure 1). Furthermore, infrared line scanners currently used in fire operations in the United States are deployed from a central location in Idaho and may be infrequently available or unavailable to a given fire incident. This can be a critical limitation, for instance, in California where fast-moving large fires can quickly develop and threaten many lives and much property. Forward-looking infrared imagers designed for surveillance have also been used locally to map fire lines, but these imagers typically have a very limited field of view and saturate at relatively low brightness values. What is needed is a low-cost, highdynamic-range infrared fire mapper, designed specifically for fire monitoring, that can be made widely and readily available and integrated into existing fire suppression operations.

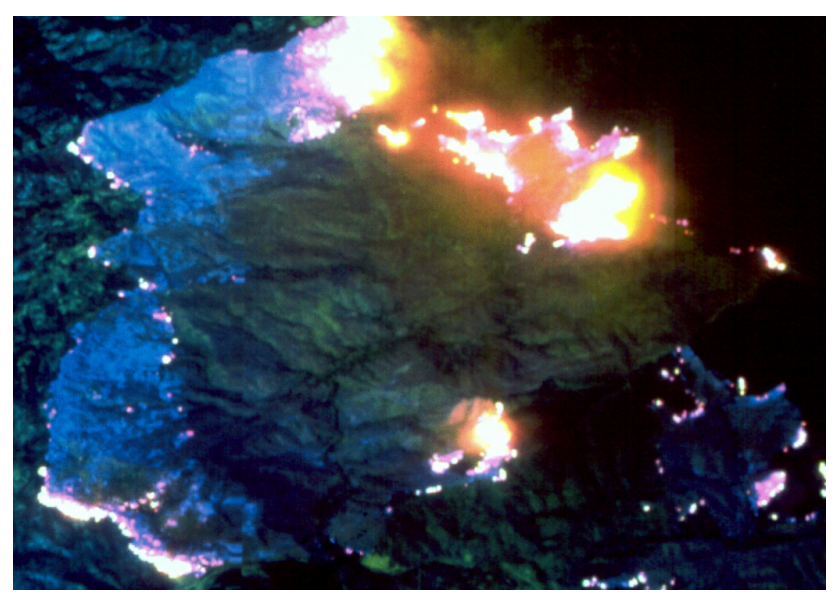

Figure 1. Color-composite infrared image of the 1985 Wheeler Fire, Los Padres National Forest, as viewed by the NASA Thematic Mapper Simulator. The major fire front at top is approximately eight

kilometers in length, yet because of the saturation in each of three infrared channels depicted, it falsely appears to be more than in a kilometer in width.

Thus, although the imager can map the fire through heavy smoke and show its location in terrain, it grossly distorts the magnitude of the fire activity and allows no estimates of fire intensity or impact.

The Forest Service Pacific Southwest Research Station and Space Instruments, Inc., have now developed a prototype thermal-imaging radiometer, the FireMapper, which was designed specifically for fire applications in research and to provide a commercially available system for fire operations. In this paper we describe the rationale and implementation of the FireMapper imaging system including design elements, user interface, calibration, and use in estimation of fire properties. In a companion paper [3] we describe some recent applications to remote wildfire measurements in California.

\section{THE FIREMAPPER SYSTEM}

The prototype FireMapper thermal-imaging radiometer is a multi-spectral instrument employing a microbolometer focal-plane array [4] manufactured in 1999 by Lockheed Martin Infrared Imaging Systems. The microbolometer array is a new technology developed under sponsorship of the Defense Advanced Research Projects Agency (DARPA) for use in the next generation of night-vision devices for the U.S. military. FireMapper requires no cryogenic cooling, as do conventional Mercury-Cadmium-Telluride detectors, and this allows for simplified instrument design and operation, especially in remote locations.

\section{FireMapper Specifications}

FireMapper incorporates multiple channels implemented through a filter wheel located between the focal-plane array and lens. Successive $327 \times 205$-element images $^{1}$ are collected in two narrow bands, with wavelengths of 8.1 to 9 $\mu \mathrm{m}$ and 11.4 to $12.4 \mu \mathrm{m}$, and a broad band encompassing this spectrum. Images are collected in each band every 5.6 seconds. In our wide-area applications, for example with ground speed of $92 \mathrm{~m} / \mathrm{s}$ (185 kts) and altitude above ground of $2770 \mathrm{~m}(9000 \mathrm{ft})$, this frequency is sufficient to produce stereo thermal-infrared imagery with a resolution of 5.1 meters. Time-based integration of the signal across multiple frames collected at $30 \mathrm{Hertz}$ is selectable to improve the ratio of signal to noise, although this feature requires a very stable platform flown at a specific ratio of velocity to altitude over the ground. As with the earlier ThermalImaging Radiometer designed by Space Instruments [5], the FireMapper uses $25-\mathrm{mm}, \mathrm{f} / 0.8$ germanium optics with an instantaneous field of view of 1.85 milliradians and total field of view of 35 degrees. Signals are digitized to 16 bits.

\section{On-board Calibration and Drift Correction}

The FireMapper performs a through-the-lens, absolute offset calibration upon user command. This calibration uses a surface-machined and black-anodized 3-inch-diameter reference blackbody with very high emissivity that is mounted in a Geneva-drive mechanism below the lens. The reference blackbody temperature, which is not controlled, is monitored by three imbedded thermistors. A reference blackbody calibration, which requires 46 seconds, is typically accomplished prior to the start of a remote-sensing flight line. The reference blackbody calibration also serves to remove image patterns caused by thermal emissions within the instrument and reflections from the band-pass filters that would otherwise seriously confound the target imagery (Figure 2). As the flat field of the blackbody is viewed during calibration, offsets are calculated and stored to set the digital number of each element to a standard value

\footnotetext{
${ }^{1}$ Less than the maximum 245 rows are collected in the along-track direction to allow for time-delay integration.
} 
of 4096. These offsets are then automatically applied to successive images. The blackbody temperature and this nominal reference number are used to calculate the intercept of the calibration function of radiance to digital number for each band during subsequent image analysis.

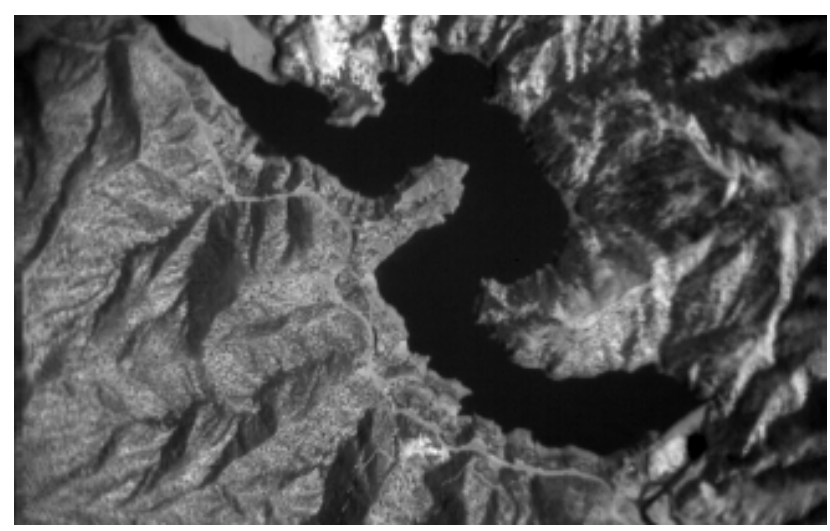

Figure 2a. Broadband thermal-infrared image of Morris Reservoir and surrounding wildlands, Angeles National

Forest, Los Angeles County, California, as viewed 4

October 2002 by the FireMapper. Distance from left to right is $2.4 \mathrm{~km}$. The Williams Fire burned hillsides above and to the right of the reservoir 10 days previously.

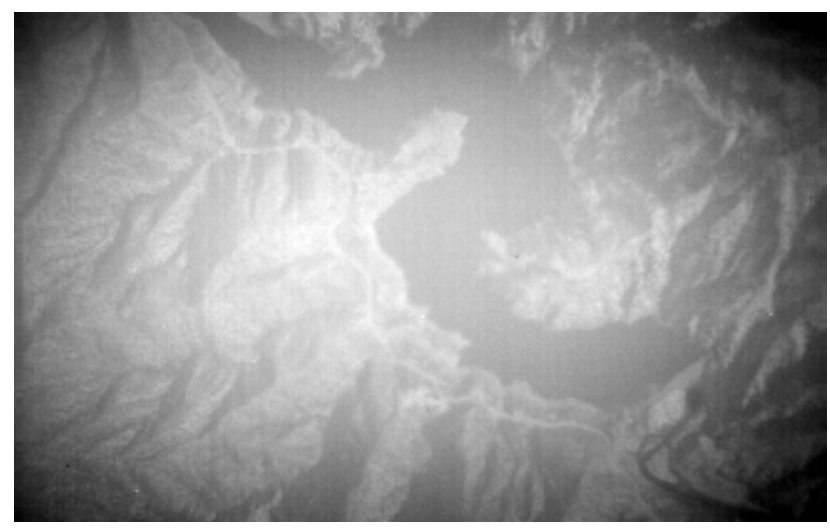

Figure $2 \mathrm{~b}$. Narrow-band, 11.4- to $12.4-\mu \mathrm{m}$, thermal image of the area depicted in 2a; imagery was collected without reference-blackbody offset calibration. Internal reflections within the FireMapper, such as shown here, are routinely removed during this in-flight procedure.

A second level of offset calibration is implemented in the FireMapper by imaging a small ambient-temperature blackbody, mounted in the filter wheel, that is viewed once every rotation of the wheel. This offset blackbody effectively removes instrument drift associated with the thermoelectric cooler that would otherwise cause substantial measurement errors, especially in the narrow-band channels (Figure 3). If uncorrected, this drift would produce unacceptable errors, especially in background temperatures, and prohibit consistent discrimination of vegetation and ash or detection of spot fires.

\section{High-Temperature Calibration}

Radiance calibrations for each of the FireMapper channels have been performed in the laboratory with a high-precision, high-temperature blackbody radiation source, model LS1250-100, manufactured by Electro Optical Industries, Inc. The blackbody radiation source had been calibrated with six primary-standard freeze-point blackbodies and an Electro Optical Industries Model 4147Z Optical Comparator. The radiation source is rated to a temperature of $1250^{\circ} \mathrm{C}$. The radiance calibration of each channel is highly linear on the instrument digital number (Table 1, Figure 4). The responses of the narrow-band channels to changing radiance are similar to each other but approximately one-eighth that of the broadband channel even though the narrow-band channels have a bandwidth one-quarter as large.

Not all elements of the FireMapper's focal-plane array saturate at the same radiance, but none saturates below a density number of 10,300, which sets an effective maximum operating range for each channel. Accordingly this sets maximum operating values or saturation points over a blackbody target at a temperature of $520^{\circ} \mathrm{C}$ for the 8.1 - to 9.0- $\mu \mathrm{m}$ channel, $1216^{\circ} \mathrm{C}$ for the 11.4- to $12.4-\mu \mathrm{m}$ channel, and $204^{\circ} \mathrm{C}$ for the broadband channel.

Instrument control and signal processing are implemented onboard the FireMapper by a series of custom-designed circuit boards located in the upper half of the instrument casing (Figure 5).

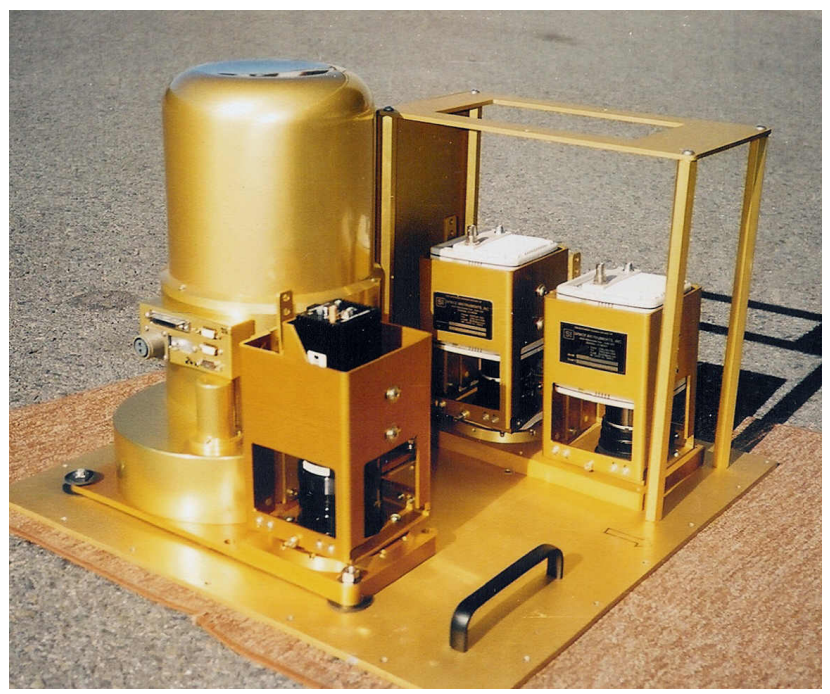

Figure 5. The FireMapper system. The FireMapper thermal-imaging radiometer is contained in the cylindrical housing at the left. Two Kodak MegaPlus cameras are at right and a Sensors Unlimited InGaAs camera is at front center. Instruments are shown on the aircraft mounting plate.

\section{Associated Cameras and System Control}

The FireMapper has been mounted as a nadir-viewing instrument aboard the Pacific Southwest Research Station's 
Airborne Sciences Aircraft, N70Z. N70Z is a twin-engine Piper Navajo model PA-31/G. FireMapper is operated as part of a multi-camera system that also includes two Kodak Megaplus 1.6i cameras, typically operated at wavelength band centers of 550 or 650 and $850 \mathrm{~nm}$, and a model SU320M digital camera manufactured by Sensors Unlimited that incorporates a $320 \times 240$ element InGaAs focal plane array and is operated at a wavelength of $1.58-\mu \mathrm{m}$. The additional cameras are operated with filter configurations similar to the Landsat Thematic Mapper bands 2, 3, 4, and 5. The InGaAs camera has total and instantaneous fields of view similar to those of the FireMapper. All cameras may be operated in stereo mode.

N70Z has been modified by installation of an open camera port, with a manually operated, retractable door, manufactured by Niyak Aviation. The aircraft is typically operated at air speeds between 135 and 185 knots and altitudes to 17,500 feet above sea level. The aircraft has also been equipped with GPS steering for navigation of precise flight lines, a mechanical damper to minimize changes in aircraft yaw, and wing vortex generators to maximize load.

Imaging by the FireMapper system is controlled through a user interface implemented in Windows NT Workstation 4.0 on a Micron Netframe 5201 server. FireMapper uses a SCSI line to communicate with the Micron 5201. Data are recorded on swappable, 36-GB Ultra3 SCSI hard drives.

The user interface provides real-time image viewing and instrument control (Figure 6). User-selectable functions include selection of cameras for data collection and recording, calibration functions for the FireMapper, frequency of imaging for the Megaplus and $1.6 \mu \mathrm{m}$ cameras, synchronizing of data collection among cameras, integration time for the $1.6 \mu \mathrm{m}$ camera, and exposure time and gain setting for the Megaplus cameras. Imagery of any one of the collected bands or cameras may be chosen for real-time display in gray scale or false color (Figure 6), with color tables customizable to control the histogram of the displayed image or to highlight desired features such as active fire fronts or spot fires. The user may also transfer an image of interest to a static viewing window or "tag" images of special interest as they are recorded to disk.

\section{FIRE MEASUREMENTS}

The FireMapper has been applied to measure active wildfires in Brazil during 2000 and in California during the 2001 and 2002 fire seasons. These observations at thermalor longwave-infrared wavelengths alone were useful in discriminating fire fronts, ash, and spot fires in tropical savanna, California chaparral, and coniferous forest (Figure 7).

In practice, the narrow-band $11.4-$ to $12.4-\mu \mathrm{m}$ channel was the most useful in mapping fire activity; it remained unsaturated across all observations including a wide range in fire activity from slow-moving ground fires in coniferous-forest to high-intensity chaparral fires with flame lengths on the order of 30 meters or greater. Both the wideband and narrow-band $8.1-$ to $9-\mu \mathrm{m}$ channels routinely saturated within flaming fronts. However, the wideband channel did provide greater discrimination of the background scene than either of the narrow bands, although the 11.4- to $12.4-\mu \mathrm{m}$ channel was generally adequate on its own for fire mapping. Background discrimination was most difficult in the narrow-band channels when observations were made through heavy smoke or beneath clouds that greatly reduced solar heating at the ground and led to a flat thermal scene. The wideband channel was also useful in mapping residual burning-which was often contained within single pixels - along fire perimeters as the fire was being brought under containment.

We examined differences in apparent blackbody temperatures, estimated from the 8.1- to $9-\mu \mathrm{m}$ and $11.4-$ to $12.4-\mu \mathrm{m}$ radiances, within a portion of the Viejas Fire, which burned in the Cleveland National Forest, San Diego County, California, on 4 January 2001. At the time of observation the fire was burning under the influence of onshore winds in chaparral. Radiances were corrected for atmospheric transmittance and path radiance as computed from radiosonde data from San Diego and the PCModWin implementation of the MODTRAN model. Images were collected from an altitude of 2800 meters above ground. Estimated temperature patterns resulting from the two channels were broadly similar within a lobe of active and recent combustion (Figure 8). Estimates from the 11.4- to $12.4-\mu \mathrm{m}$ channel were on average $59^{\circ} \mathrm{C}$ greater than those from the 8.1- to $9-\mu \mathrm{m}$ channel for areas estimated (at the longer wavelength) to be hotter than $300^{\circ} \mathrm{C}$; the elevation in estimated temperature at the longer wavelength ranged from $10^{\circ}$ to $110^{\circ} \mathrm{C}$ across ninety percent of these hot pixels. The discrepancies were apparent across areas of tens of meters and were unrelated to any pixel-to-pixel noise in the FireMapper. Temperature estimates for unburned ground in the vicinity of the fire were quite similar between the two narrow-band channels.

Across the several wildland fires we have monitored, the greatest blackbody temperature estimated from the $11.4-$ to $12.4-\mu \mathrm{m}$ radiance was approximately $850^{\circ} \mathrm{C}$. 


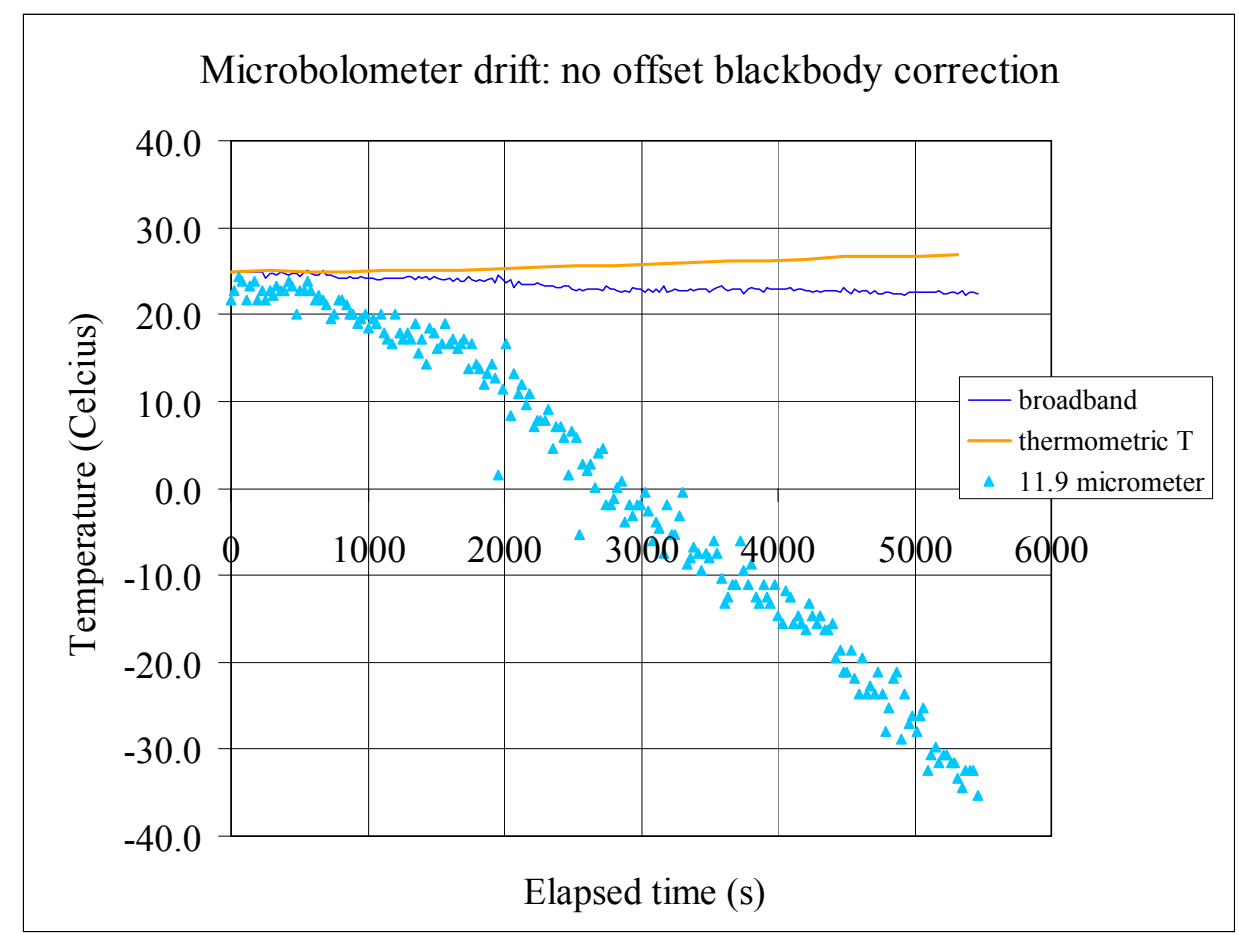

Figure 3. Drift in the microbolometer system with the offset-blackbody correction disabled. Drift in the microbolometer array produced a $62^{\circ} \mathrm{C}$ error in scene temperature in a narrowband channel when viewing the reference blackbody for 90 minutes. Temperatures estimated from the broadband channel and from a thermocouple are also shown. The "11.9 micrometer" annotation refers to the 11.4 - to $12.4-\mu \mathrm{m}$ channel.

Table 1. Linear regression coefficients and statistics for radiance, $B\left(\mathrm{~J} \mathrm{~m}^{-2} \mathrm{~s}^{-1} \mathrm{sr}^{-1} \mu \mathrm{m}^{-1}\right)$, as a function of digital number, dn: $B=\beta_{0+} \beta_{1}(\mathrm{dn})$. Shown are the point estimates (Pt. Est.) and 95\% confidence intervals ( $95 \%$ c.i.) for the regression coefficients, the proportion $\left(\mathrm{r}^{2}\right)$ of the sample variance accounted for by the regression, and the number $(\mathrm{n})$ of temperatures used.

\begin{tabular}{l|rrrrc} 
Channel & & $\beta_{0}$ & $\beta_{1}$ & $\mathrm{r}^{2}$ & $\mathrm{n}$ \\
\hline 8.1 to $9.0 \mu \mathrm{m}$ & Pt. Est. & -226.9 & 0.0574 & 0.9999 & 10 \\
& $95 \%$ c.i.: & -227.7 & 0.0573 & & \\
& & -226.1 & 0.0575 & & \\
\hline 11.4 to $12.4 \mu \mathrm{m}$ & Pt. Est. & -259.4 & 0.0652 & 0.9999 & 17 \\
& $95 \%$ c.i.: & -261.9 & 0.0649 & & \\
& & -257.0 & 0.0656 & & \\
\hline Broadband, 8.1 to $12.4 \mu \mathrm{m}$ & Pt. Est. & -25.6 & 0.00832 & 0.9999 & 4 \\
& $95 \%$ c.i.: & -26.4 & 0.00821 & & \\
& & -24.8 & 0.00842 & &
\end{tabular}




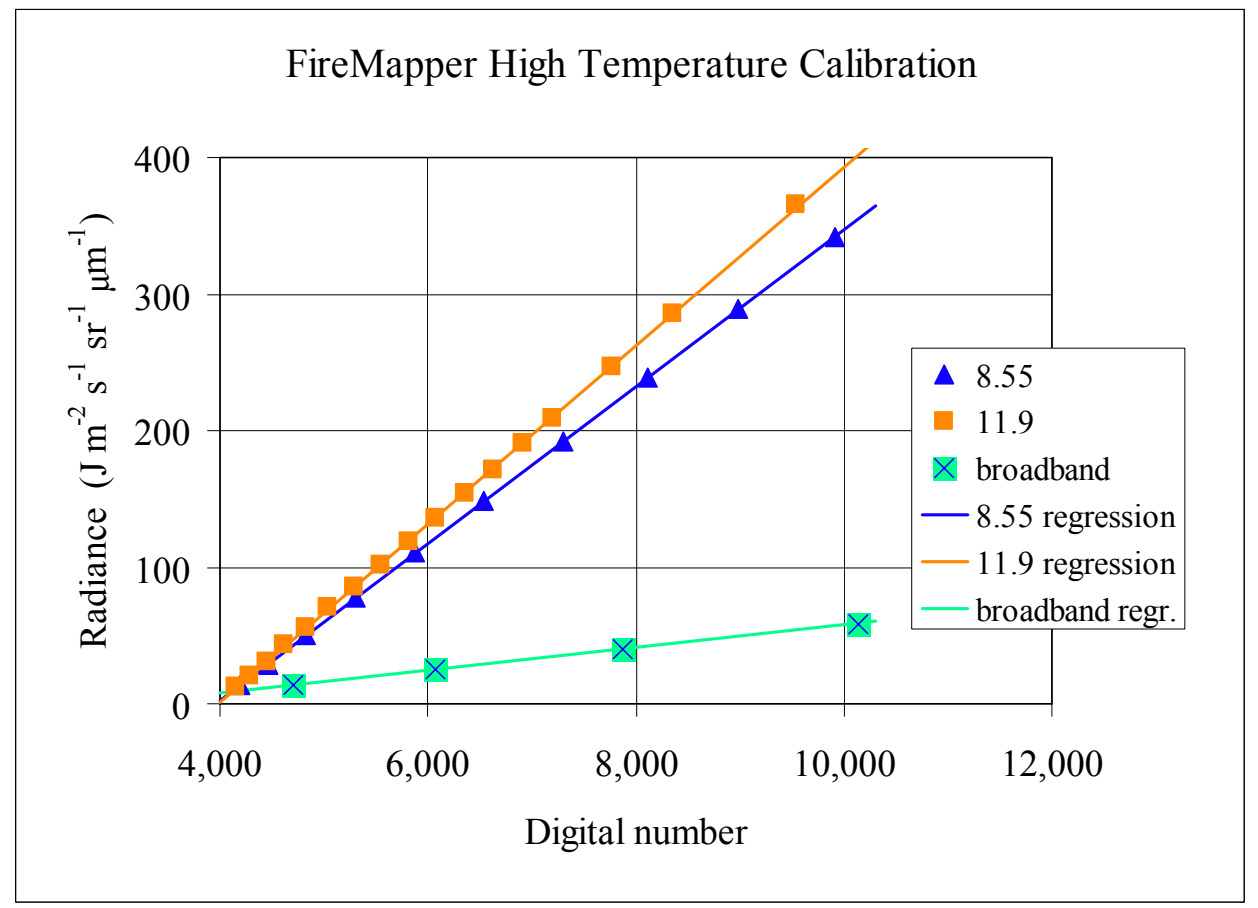

Figure 4. Calibration of the FireMapper with a precision, high-temperature, blackbodyradiation source. Some elements of the focal-plane array saturate above a digital number of 10,300 . The " 8.55 " annotation is the 8.1- to $9.0-\mu \mathrm{m}$ channel; " 11.9 " is the 11.4 - to $12.4-\mu \mathrm{m}$ channel.

Table 2. Camera characteristics for the FireMapper system operated aboard the Forest Service Airborne Sciences Aircraft, N70Z.

\begin{tabular}{|c|c|c|c|c|}
\hline Camera and channel & Wavelength & Array size & $\begin{array}{l}\text { Instantaneous } \\
\text { field of view }\end{array}$ & $\begin{array}{l}\text { Cross track } \\
\text { field of } \\
\text { view }\end{array}$ \\
\hline FireMapper & & $327 \times 245^{2}$ & $1.85 \mathrm{mrad}$ & $35^{\circ}$ \\
\hline Channel 1 & Offset blackbody & & & \\
\hline Channel 2 & $\begin{array}{c}8.1 \text { to } 9.0 \mu \mathrm{m} \text { (same band center } \\
\text { as MODIS channel 29) }\end{array}$ & & & \\
\hline Channel 3 & $\begin{array}{c}11.4 \text { to } 12.4 \mu \mathrm{m} \text { (same band } \\
\text { center as MODIS channel } 32 \text { ) }\end{array}$ & & & \\
\hline Channel 4 & $\begin{array}{l}\text { Broadband, } 8.1 \text { to } 12.4 \mu \mathrm{m} \\
\text { (similar to Landsat Thematic } \\
\text { Mapper band 6) }\end{array}$ & & & \\
\hline $\begin{array}{l}\text { Kodak MegaPlus 1.6i (with } \\
\text { 20-mm lens) }\end{array}$ & & $1528 \times 1024$ & $0.45 \mathrm{mrad}$ & $38^{\circ}$ \\
\hline Camera A & 515 to $585 \mathrm{~nm}$ or 615 to $685 \mathrm{~nm}$ & & & \\
\hline Camera B & 815 to $885 \mathrm{~nm}$ & & & \\
\hline $\begin{array}{l}\text { Sensors Unlimited, Inc. } \\
\text { InGaAs model SU320M }\end{array}$ & $1.50-1.65 \mu \mathrm{m}$ & $320 \times 240$ & $1.6 \mathrm{mrad}$ & $29^{\circ}$ \\
\hline
\end{tabular}

2 operated at $327 \times 205$ 


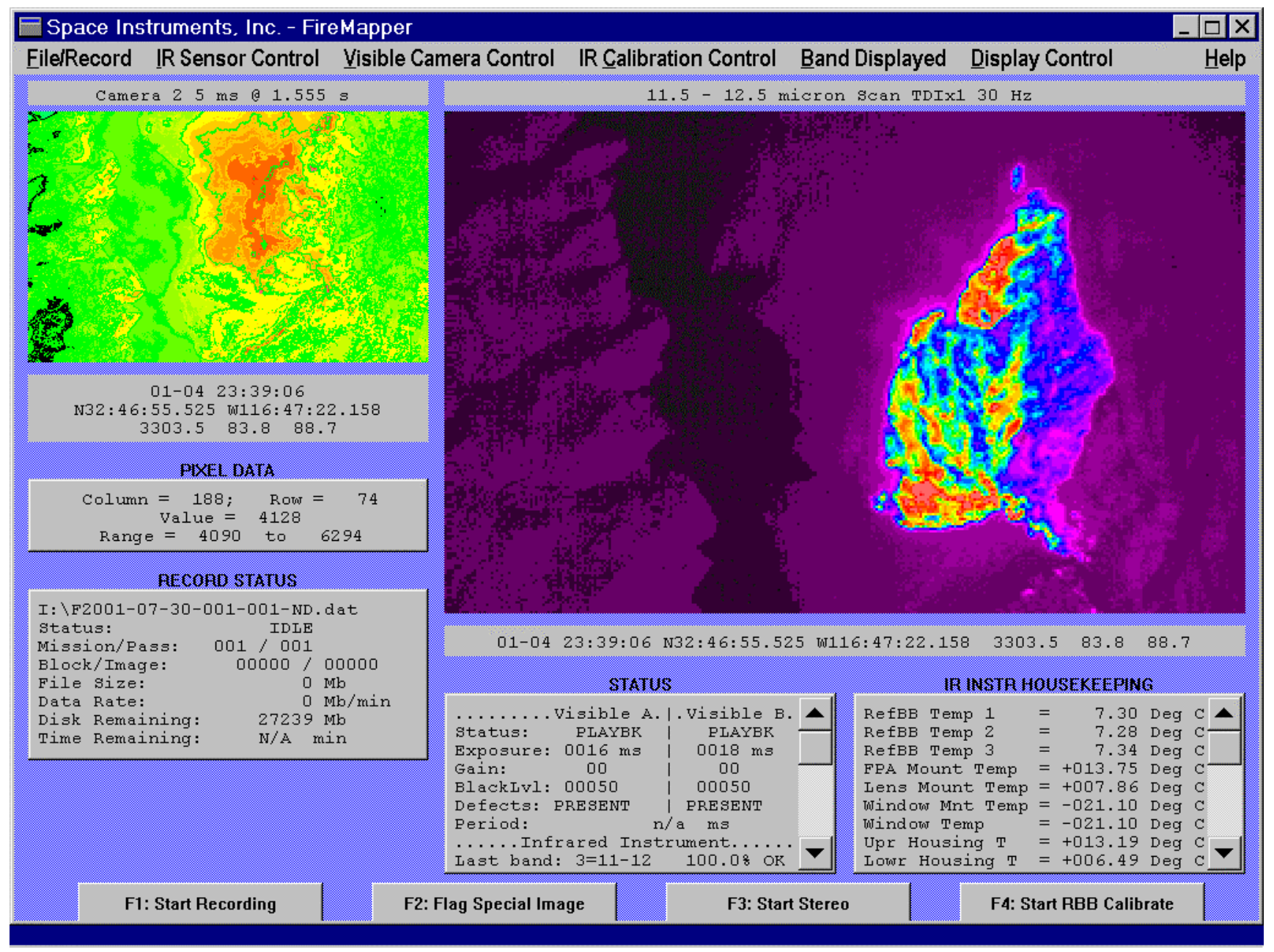

Figure 6. The FireMapper user interface as viewed for a portion of the 2001 Viejas Fire. The interface features dual image displays to allow comparison of the current image with one previously selected from the data stream. Bands from any operating camera may be displayed using a user-defined lookup table. System status and housekeeping data are shown as well as aircraft location, time, GPS-derived altitude, ground speed, and track. System functions are selectable through pulldown menus or buttons for the most commonly accessed functions. Playback of previously recorded imagery is also possible through the interface program. 


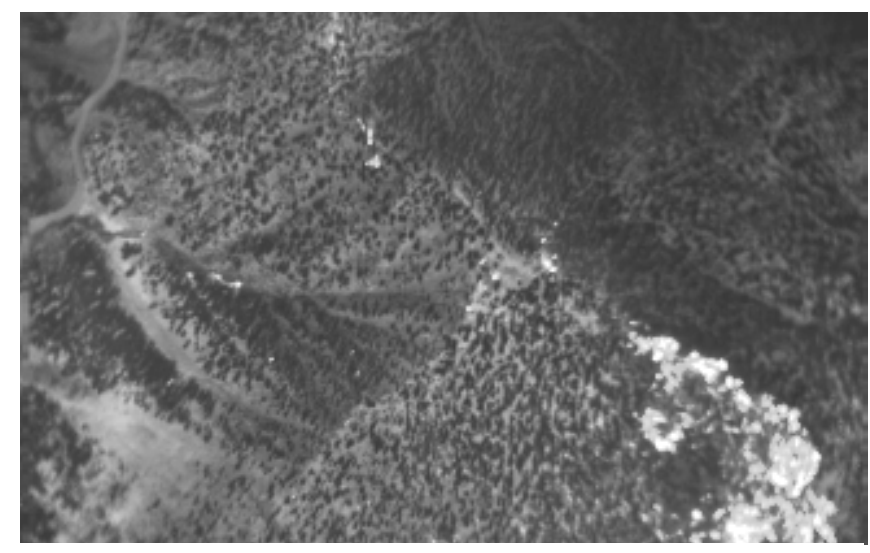

Figure 7a. Broadband thermal- infrared image of the 2002 Curve Fire, Angeles National Forest, California, as viewed by the FireMapper thermal-imaging radiometer. Areas of active or recent combustion in this sparse coniferous forest are bright, for example, at lower right in the image. Dark spots are individual tree canopies, which are cool in relation to the surrounding bare ground. Note the clear definition of State Highway 2 at upper left, talus slopes below the highway in this very steep terrain, and spot fires at left and top center. Areas of active fire are typically saturated in the broadband channel of the FireMapper.

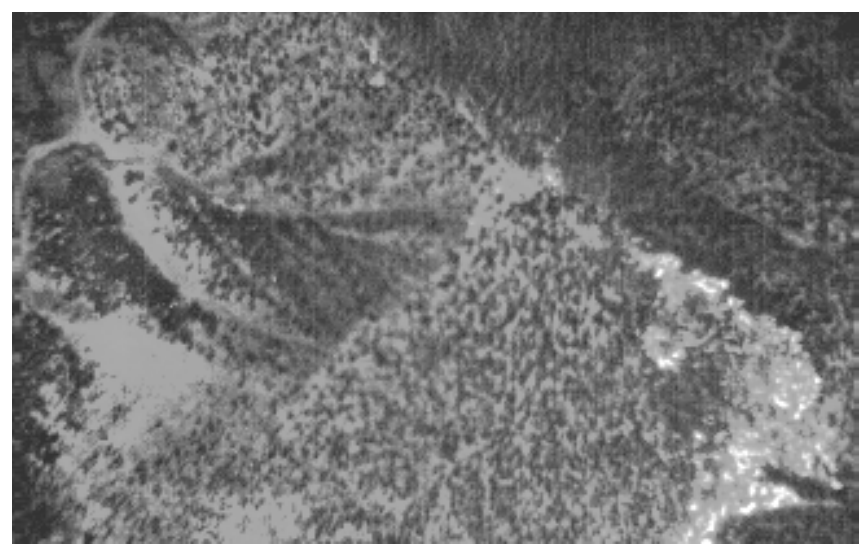

Figure 7b. 11.4- to $12.4-\mu \mathrm{m}$ image of the area depicted in Figure 7a. Data are unsaturated in this channel, in which the brightest areas show a good relation to areas of active combustion, but contrast is reduced in areas of normal earth temperatures. Major terrain features are clearly visible.

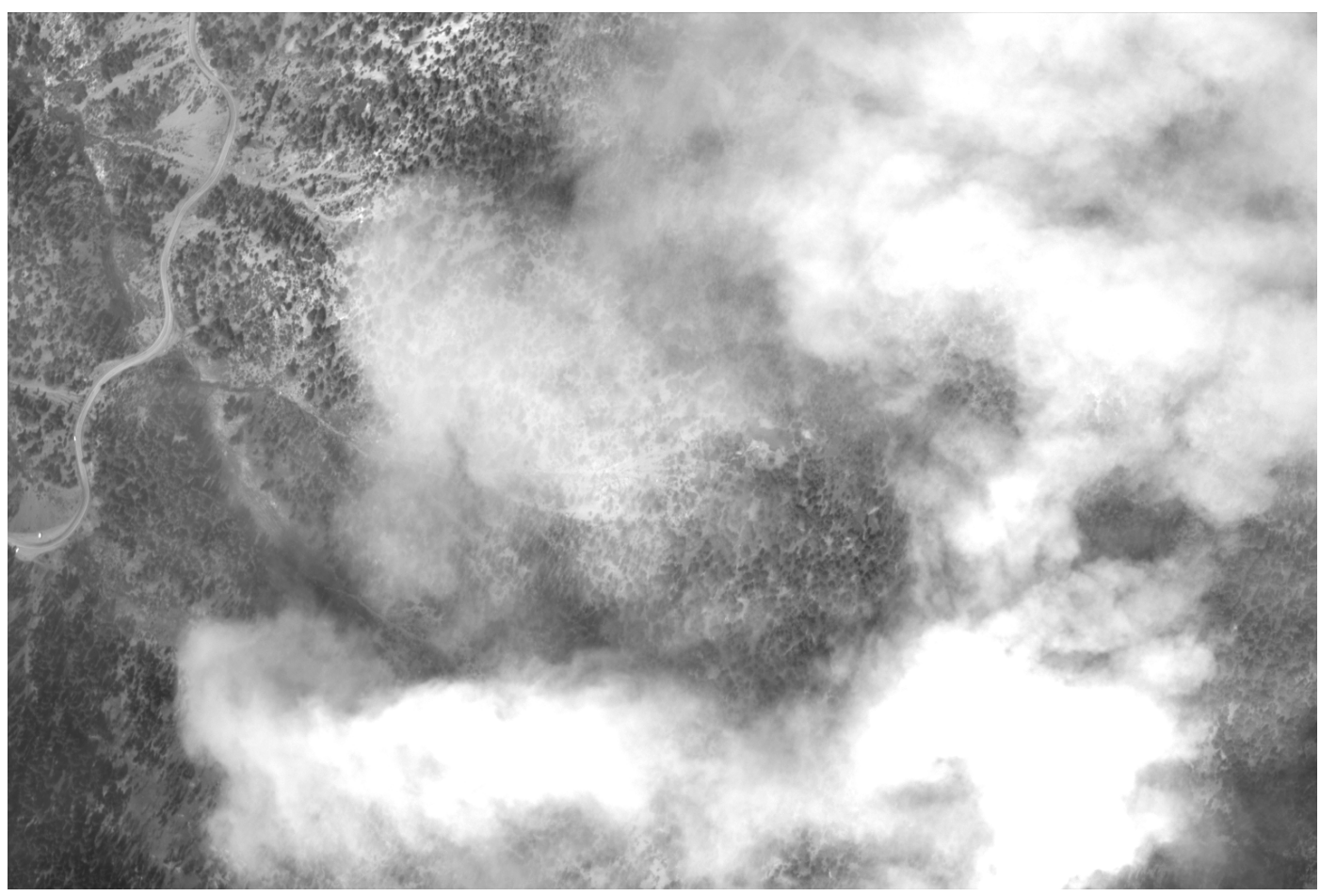

Figure $7 \mathrm{c}$. Visible-light $(550 \mathrm{~nm})$ image, shown at $45 \%$ of full resolution as a comparison with the thermal imagery of Figures $7 \mathrm{a}$ and $7 \mathrm{~b}$. The image was collected by a MegaPlus 1.6i camera. Note the obscuring smoke and correspondence of individual trees between the visible and thermal images. 


\begin{tabular}{|c|c|c|c|c|c|c|c|c|c|c|c|c|c|c|c|c|c|c|c|c|c|c|c|c|}
\hline 32 & 31 & 31 & 31 & 33 & 33 & 35 & 35 & 36 & 41 & 45 & 48 & 54 & 62 & 71 & 79 & 85 & 80 & 71 & 64 & 56 & 50 & 48 & 46 & \\
\hline 32 & 32 & 32 & 31 & 35 & 35 & 37 & 38 & 40 & 46 & 54 & 64 & 89 & 43 & 90 & 151 & 17 & 99 & & & 59 & & 46 & 45 & \\
\hline 32 & 34 & 34 & 34 & 34 & 36 & 38 & 41 & 45 & 55 & 88 & 75 & 299 & & 343 & T & & 182 & & & 7 & & , & 44 & \\
\hline 35 & 34 & 36 & 36 & 36 & 38 & 41 & 46 & 54 & 103 & 40 & 8 & 60 & . & 301 & 89 & 52 & 76 & 39 & & 79 & & 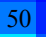 & 45 & \\
\hline 34 & 36 & 36 & 36 & 38 & 39 & 43 & 52 & 25 & 266 & 23 & 332 & 33 & 1 & 312 & 6 & 55 & 3 & 3 & & $T$ & & 3 & 48 & \\
\hline 36 & 36 & 36 & 37 & 41 & 43 & 48 & 65 & 212 & 303 & 27 & 297 & 92 & 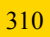 & 323 & 332 & 43 & 386 & 460 & & 11 & & & 50 & \\
\hline 36 & 35 & 39 & 39 & 42 & 46 & 56 & 7 & 7 & 6 & 5 & 9 & 9 & 4 & 312 & 0 & 9 & 1 & 3 & 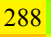 & 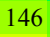 & & & 54 & \\
\hline 37 & 37 & 41 & 42 & 46 & 52 & 82 & 10 & 279 & 348 & 340 & 278 & 277 & 94 & 305 & 337 & 337 & 394 & 463 & 66 & 221 & 15 & 73 & 2 & \\
\hline 37 & 40 & 42 & 46 & 54 & 95 & 31 & 21 & 351 & 86 & 36 & 292 & 80 & y & 320 & 39 & 59 & 376 & 20 & 2 & 35 & & o & 8 & \\
\hline 39 & 43 & 48 & 55 & 02 & 1 & 32 & 57 & 378 & 368 & 354 & 314 & 15 & 3 & 326 & 330 & 324 & 318 & 354 & 28 & 181 & 0 & 5 & 74 & \\
\hline 43 & 47 & 53 & 60 & 70 & 37 & 56 & 46 & 365 & 352 & 322 & 313 & 350 & 18 & 324 & 314 & 299 & 314 & 333 & 240 & 155 & 116 & 93 & 73 & \\
\hline 48 & 5 & & & & & & & & & & & & & & & & & & & & & & & \\
\hline 55 & 98 & 0 & 10 & 52 & 7 & 17 & 14 & 34 & 329 & 12 & 321 & 325 & 29 & 355 & 364 & 363 & 313 & 242 & 17 & 147 & 115 & 38 & 68 & \\
\hline 61 & 14 & 1 & 17 & 3 & 6 & 3 & 63 & 344 & 322 & 07 & 322 & 46 & & 375 & 353 & 371 & 301 & 218 & 189 & 57 & 9 & 91 & 75 & \\
\hline 94 & 178 & & 92 & 321 & & & 365 & & 3 & 0 & 342 & 356 & & 411 & 394 & 438 & 458 & 351 & 22 & 152 & 107 & 04 & 72 & \\
\hline 163 & 21 & ניק & 37 & $J$ & 379 & 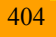 & 2 & 36 & 34 & 33 & 330 & 354 & 379 & 442 & 555 & 593 & 486 & 261 & 14 & 101 & & 69 & 63 & \\
\hline 250 & 57 & 271 & 36 & 51 & 357 & 83 & 36 & 363 & 345 & 45 & 334 & 359 & 418 & 356 & 439 & 425 & 268 & 140 & & 67 & 80 & 56 & 55 & \\
\hline 199 & 79 & 98 & 88 & 328 & & 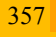 & 85 & 363 & 386 & 396 & 408 & 406 & 8 & 217 & 155 & 143 & 109 & 7 & & 61 & 58 & 54 & 50 & \\
\hline 122 & 40 & 138 & 76 & 258 & 307 & 354 & 369 & 361 & 382 & 421 & 381 & 290 & 200 & 123 & 85 & 77 & 71 & 62 & & 72 & 66 & 55 & 52 & \\
\hline 131 & 89 & 98 & 67 & 170 & 48 & 325 & 362 & 380 & 386 & 368 & 256 & 156 & 100 & 76 & 70 & 70 & 76 & 73 & 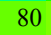 & 87 & 75 & 77 & 60 & \\
\hline
\end{tabular}

Figure 8a. Map of apparent blackbody temperatures (in Celcius), estimated from radiance at 8.1 to $9.0 \mu \mathrm{m}$, for a portion of the Viejas Fire, 4 January 2001, Cleveland National Forest, San Diego County, California. Cells in this graphic each represent an area of $25 \mathrm{~m}^{2}$. Here a chaparral fire front has recently progressed from lower left to upper right. Areas less than $150^{\circ} \mathrm{C}$ at far right are associated with the smoke column. Pixels outlined by a black border were saturated so that temneratures were underestimated there.

\begin{tabular}{|c|c|c|c|c|c|c|c|c|c|c|c|c|c|c|c|c|c|c|c|c|c|c|c|c|}
\hline 29 & 29 & 31 & 30 & 28 & 29 & 31 & 33 & 33 & 38 & 41 & 47 & 54 & 65 & 84 & 94 & 86 & 78 & 77 & 83 & 80 & 69 & 54 & 46 & \\
\hline 32 & 30 & 31 & 31 & 30 & 31 & 33 & 36 & 7 & 45 & 51 & 70 & 114 & & 226 & & & & & & & & $=7$ & & \\
\hline 29 & 30 & 31 & 30 & 33 & 34 & 34 & 36 & 41 & 55 & 100 & 89 & 00 & 40 & 57 & & 01 & & & 222 & & & & 47 & \\
\hline 31 & 33 & 33 & 30 & 33 & & 36 & 30 & 55 & 119 & & 3 & & & & & 34 & & 32 & & & & & 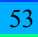 & \\
\hline 31 & 33 & 33 & 34 & 35 & 36 & 40 & 51 & 126 & 41 & 06 & 57 & 67 & 376 & 381 & 95 & 434 & 79 & 37 & 01 & 44 & & 84 & & \\
\hline 31 & 31 & 33 & 33 & 37 & 40 & 41 & 75 & 209 & 05 & 352 & 342 & $4 J$ & 360 & 374 & 90 & 414 & 460 & 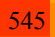 & 421 & 265 & & & & \\
\hline 33 & 33 & 36 & 20 & 10 & & 55 & & & 341 & 7 & 0 & 27 & 57 & 7 & 2 & & & & & & & & & \\
\hline 35 & 36 & 38 & 40 & 44 & 55 & 105 & 20 & 314 & 394 & 375 & 328 & 319 & 346 & 372 & 405 & 407 & 435 & 469 & 460 & 291 & 15 & 96 & 31 & \\
\hline 37 & 37 & 39 & 44 & 56 & 120 & 21 & & 67 & 19 & 79 & 39 & 320 & 348 & 369 & 1 & 402 & 409 & & 446 & 287 & & & S & \\
\hline 37 & 39 & 44 & 63 & 34 & 37 & 33 & 6 & 407 & 398 & 377 & 343 & 348 & 365 & 373 & 85 & 392 & 403 & 148 & 390 & 247 & 1 & 98 & 84 & \\
\hline 40 & 42 & 60 & 149 & 61 & 29 & 74 & 1 & 393 & 392 & 377 & 352 & 369 & 350 & 379 & 396 & 410 & 416 & 450 & 341 & 210 & 12 & 3 & 81 & \\
\hline 39 & 52 & & & & & & & & & & & 3 & & 90 & & & & & & 3 & & & 79 & \\
\hline 47 & 108 & & 27 & 96 & 318 & 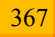 & & 415 & 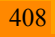 & 0 & 370 & 36 & 364 & 401 & 43 & 451 & 421 & & 219 & 146 & & & 70 & \\
\hline 60 & 42 & & 56 & 77 & 5 & 32 & 26 & 435 & 428 & 16 & 410 & 398 & 386 & 422 & 54 & 176 & 407 & & 209 & 164 & & 94 & 78 & \\
\hline 99 & & & 307 & 32 & 374 & & & 452 & 458 & 49 & 434 & 407 & 417 & 443 & 506 & 554 & 535 & & 258 & 157 & 11 & 07 & & \\
\hline & & & 46 & 77 & 05 & 436 & 445 & 451 & 448 & 436 & 423 & 406 & 420 & 462 & 575 & 639 & 611 & 585 & 220 & 124 & & & 50 & \\
\hline 7 & 71 & & 57 & 384 & 106 & 436 & 446 & 450 & 442 & 434 & 409 & 411 & 434 & 408 & 456 & 493 & 402 & 271 & 142 & 74 & & 56 & 53 & \\
\hline & & & 307 & 358 & 383 & 419 & 454 & 455 & 451 & 454 & 454 & 427 & 380 & 262 & 240 & 231 & 196 & 126 & 76 & 61 & & 4 & 53 & \\
\hline 10 & 71 & 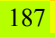 & 30 & 286 & 336 & 402 & 444 & 451 & 461 & 484 & 446 & 349 & 253 & 167 & 109 & 85 & 79 & 70 & 72 & 69 & & 61 & 54 & \\
\hline 154 & 70 & 81 & 182 & 220 & 274 & 361 & 427 & 458 & 461 & 456 & 339 & 234 & 142 & 93 & 70 & 6 & 65 & 77 & 8 & 84 & 7 & 62 & 51 & \\
\hline
\end{tabular}

Figure 8b. Map of apparent blackbody temperatures (in Celcius), estimated from radiance at 11.4 to $12.4 \mu \mathrm{m}$, for the area shown in Figure 8a. Temperature patterns are broadly similar to those above, but are on average $59^{\circ} \mathrm{C}$ greater for the hotter areas. 


\section{DISCUSSION}

\section{Measuring flame properties}

As we have recently described elsewhere [2], wildland fires present a complex remote-sensing target comprised of a flaming front, ash, residual flaming combustion, smoldering of larger biomass elements, and unburned vegetation. Remote sensing can measure the radiation upwelling from this complex at specific infrared wavelengths, longer than approximately $1.5 \mu \mathrm{m}$, which will largely penetrate smoke (but not water clouds). The challenge is to deduce meaningful properties of wildland fires, and especially the flaming front, based on these brightness measurements in the infrared.

To estimate flame properties by remote sensing it has been assumed that the radiant emissions from flames are dominated by radiation from glowing soot particles and that hot soot and ash approximate gray-body radiators with high emissivity [6] (Figure 9). With these assumptions, the temperature of a uniform area can be estimated from its brightness at two infrared wavelengths by simultaneously solving Planck functions for each wavelength $[7,8]$, and estimating the target emissivity from that temperature and the brightness at one wavelength. Total brightness or radiant intensity across all wavelengths of light can then be estimated from the temperature and an integration of the Planck function.

Flames in biomass fires may be so optically thin that upwelling radiation as viewed by a remote sensor encompasses light emitted from hot soil beneath the flames as well as from the glowing soot particles. For large flames or those of high soot-particle volume, such as found in aviation-fuel fires, upwelling radiation may originate from and reflect the temperature of upper flames alone [9]. Yet even with long flame lengths, high-temperature flames may instantaneously fill only a fraction of a remote-sensing pixel, even for pixels within a flaming front. Thus a parameter representing the product of emissivity and fractional area of fire within a pixel must be estimated in order to represent the radiance or brightness of a fire, and a method using radiance measurements at three wavelengths may be required to extract the flame properties [10].

From the two-channel method and measured radiances at wavelengths of $1.63 \mu \mathrm{m}$ and $3.9 \mu \mathrm{m}$, flame temperatures have been estimated that occasionally exceeded $1300^{\circ} \mathrm{C}$ along the leading edge of fires in tropical savanna or forest [2]. More than ninety percent of the radiant energy in these fires was associated with temperatures from $500^{\circ}$ to $1100^{\circ}$ C. Values of the combined flame emissivity and fractional area were generally low in savanna fires [2], even when the fire was viewed at very high resolution; one-half of the radiant flux density was associated with values less than $0.09 \mathrm{~m}^{2} / \mathrm{m}^{2}$ and ninety-five percent of the radiant flux density was associated with values less than $0.26 \mathrm{~m}^{2} / \mathrm{m}^{2}$. Values of the emissivity-fractional area parameter were occasionally as great as 1.0 in burning logging slash. Thus even though the observed flames were quite hot, they were not especially bright in the mid-wave infrared when compared with a classical, solid radiator. This is consistent with the hypothesis that flames were either optically thin or spatially heterogeneous at scales from one to a few meters.

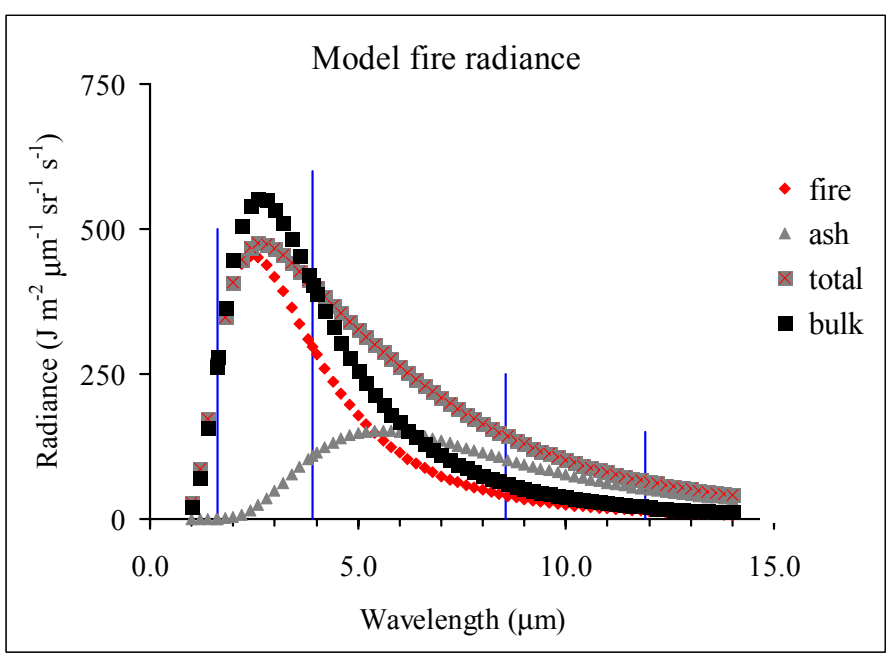

Figure 9. Expected brightness of a hypothetical pixel viewing a savanna fire at high resolution and across different infrared wavelengths. Included in the pixel is the blackbody radiation from hot ash $\left(250^{\circ} \mathrm{C}\right)$, which covers 95 percent of the pixel, and from flames with temperature of $900^{\circ} \mathrm{C}$ and emissivity/fractional area of 0.05 . The indicated total radiance is shown as a function of wavelength, as is the radiance calculated from the apparent bulk temperature $\left(820^{\circ} \mathrm{C}\right)$ and emissivity/fractional area (0.09) estimated from infrared channels at 1.63 and $3.9 \mu \mathrm{m}$. The assumed scenario reproduces average conditions previously observed in savanna fires [2]. Here the flame radiance dominates the

$1.63-\mu \mathrm{m}$ radiance, but makes a relatively small contribution to the $11.9-\mu \mathrm{m}$ radiance. The blackbody temperature estimated from the total radiance at $11.9 \mu \mathrm{m}$ was $290^{\circ} \mathrm{C}$.

Other important fire properties such as the vertical air velocity in flames have been related to flame temperature, the combined flame emissivity and fractional area, and geometry of the flame front [2]. From such information we have modeled carbon and heat output from fires as a function of their temperature and used these values with the rate of area spread to successfully estimate fuel consumption for three contrasting large fires in Brazil [2].

Temperatures within active fire fronts as measured by the FireMapper are consistent with those obtained at the soil surface beneath flaming combustion [11, 12], and it appears that radiation from a high-emissivity, hot ash surface dominates that from optically thin flames at these wavelengths. Thus FireMapper primarily gives an estimate 
of the temperature of hot ash and ground beneath a flaming front.

Blackbody-temperature spatial patterns from the 11.4- to $12.4-\mu \mathrm{m}$ radiance of the Viejas Fire were similar to and showed good correspondence with those from the 8.1- to 9$\mu \mathrm{m}$ radiance, but temperatures for high-temperature pixels were on average $59^{\circ} \mathrm{C}$ higher from the longer of these wavelength bands. This modest mismatch between the channels would cause the two-channel method, which has been used with short- and mid-wave infrared wavelengths, to produce unrealistically low temperature estimates and an anomalous emissivity-fractional area parameter greater than one. Thus, with a thermal-infrared measurement, application of a simple blackbody model appears to provide the best estimates of temperature within fire fronts and over recently burned ground. The discrepancy in blackbody temperature estimates between the channels at the leading edge of the fire appears to be due partly to the time lag (2.8 s) between measurements and fire movement over the interval. The more modest discrepancy behind the fire front may be due to elevated absorption of the 8.1- to $9-\mu \mathrm{m}$ radiation by high levels of carbon dioxide or other trace gases within flames or the lower fire plume. Such absorption could not be accounted for by the MODTRAN corrections for differences in transmittance and path radiance in the ambient atmosphere.

Although the FireMapper does not appear to directly measure flame properties, its quantitative measurement of surface temperatures within fire fronts and the extended fire area provide a useful measure of fire intensity, both in the maximum temperatures reached and duration of those temperatures behind the progressing fire front. Furthermore, these surface temperatures are expected to scale with the temperature and radiance of the flames, so it may be possible to develop scaling relations between the two and use the thermal infrared - and FireMapper - alone to estimate and monitor wildfire fuel consumption and energy flux rates.

In future applications we will test simultaneous measurement of fire radiances at both longwave and midwave infrared wavelengths, using the FireMapper, a new FireMapper 2.0 thermal radiometer, and the Sensors Unlimited 1.58- $\mu \mathrm{m}$ camera. The 850-nm MegaPlus camera will provide high-resolution imagery of flame geometry concurrently with the infrared imagery for those fires not obscured by smoke.

\section{Future Development}

The Forest Service and Space Instruments are now developing the FireMapper 2.0 specifically for use in fire suppression operations and fire measurement. The development is applying lessons from the prototype FireMapper to provide faster imaging, a smaller and lighter instrument package, a simplified user interface, and more robust and mechanically simplified calibration functions.

\section{ACKNOWLEDGMENTS}

Development of the FireMapper has been supported by a grant from the USDA Small Business Innovative Research Program, the U.S. National Fire Plan, Forest Service International Programs, and Research Joint Venture Agreements between the Forest Service Pacific Southwest Research Station and Space Instruments, Inc. We wish to acknowledge the technical support of FireMapper operations by Robert Lockwood, Robert Tissell, and Robert Lamar and the contributions made by Ron Grush, George Houghton, Lee Scotese, Gary Noyes, Glen Mounce, Bill Grush, and Ken Cashman of Space Instruments, Inc., in the design and fabrication of the FireMapper system.

Trade names, commercial products, and enterprises are mentioned solely for information. No endorsement by the U.S. Government is implied. FireMapper is a trademark of Space Instruments, Inc. This article was written and prepared by U.S. Government employees on official time, and it is therefore in the public domain and not subject to copyright.

\section{REFERENCES}

[1] R. C. Rothermel.. "A mathematical model for predicting fire spread in wildland fuels," U.S Department of Agriculture, Intermountain Forest and Range Experiment Station, 40 p., 1972

[2] P. J Riggan, R. N. Lockwood, R. G. Tissell, J. A. Brass, J. A. R. Pereira, H. S. Miranda, A. C. Miranda, T. Campos, and R. Higgins. "Remote measurement of wildfire energy and carbon flux," Submitted to Ecological Applications, 2002

[3] P. J. Riggan, R. G. Tissell, and J. W. Hoffman. "Application of the FireMapper ${ }^{\mathrm{TM}}$ thermal-imaging radiometer for fire suppression," Proceedings of the IEEE Aerospace Conference, Big Sky, Montana, paper no. 1523, 2003

[4] R. A. Wood. "High-Performance Infrared Thermal Imaging with Monolithic Silicon Focal Planes Operating at Room Temperatures," Proceedings IEDM, Washington DC, December 6, 1993

[5] P. J. Riggan and J. W. Hoffman. "Field Applications of a Multi-spectral, Thermal Imaging Radiometer," Proceedings of the IEEE Aerospace Conference, Aspen, Colorado, paper no. 168,1999

[6] W. L. Wolfe and G. J. Zissis (eds.), The Infrared Handbook, Ann Arbor, Michigan: The Infrared Information Analysis Center, Environmental Research Institute of Michigan, 1978

[7] M. Matson and J. Dozier, "Identification of Subresolution High Temperature Sources Using a Thermal 
IR Sensor," Photogrammetric Engineering and Remote Sensing 47:1311-1318, 1981

[8] P. J. Riggan, J. A. Brass, and R. N. Lockwood. "Assessing fire emissions from tropical savanna and forests of central Brazil," Photogrammetric Engineering and Remote Sensing 59(6): 1009-1015, 1993

[9] L. Gritzo, personal communication

[10] P. J. Riggan, J. W. Hoffman, and J. A. Brass. "Estimating fire properties by remote sensing," Proceedings of the IEEE Aerospace Conference, Big Sky, Montana, paper no. 519, 2000

[11] H. S. Miranda, E. P. Rocha e Silva, and A. C. Miranda. "Comportamento do fogo em queimadas de campo sujo," $\mathrm{p}$ 1-10, In: Anais do Simpósio Impacto das Queimadas sobre os Ecossistemas e Mudanças Globais. $3^{0}$ Congresso de Ecologia do Brasil, 6 a 11 de outubro de 1996, Brasília-DF, 1996

[12] P. J. Riggan, F. H. Weirich, L. F. DeBano, P. M. Jacks, R. N. Lockwood, C. Colver, and J. A. Brass. "Effects of fire severity on nitrate mobilization in watersheds subject to chronic atmospheric deposition," Environmental Science and Technology 28(3):369-375, 1994

\section{CURRICULUM VITAE}

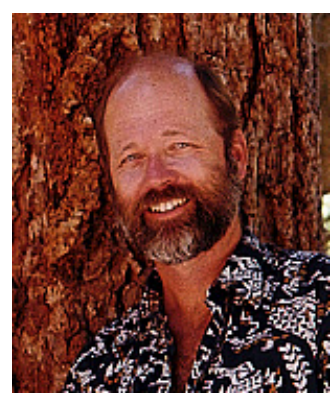

Philip Riggan is a scientist with the USDA Forest Service, Pacific Southwest Research Station, at the Forest Fire Laboratory in Riverside, California. He holds a Bachelor of Science degree in chemistry from San Diego State University and a Ph.D. from the College of Forest Resources at the University of Washington. His research has included development of technology for remote sensing of the dynamics of wildland fires, the impact of atmospheric deposition and fire severity on watershed processes, and the potential effects of wildland and agricultural fires on global climate change. Since 1991 he has been principal investigator of a bilateral program of the Forest Service and the Brazilian Federal Institute of the Environment and Natural Resources (IBAMA) that is assessing impacts of fire and environmental change in tropical forest and savanna of Brazil.

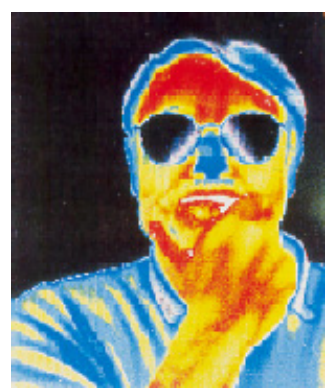

James Hoffman has been Technical Director for Space Instruments, Inc., since 1980. He has over 25 years of experience in the design of electro-optical instruments for remote sensing and surveillance. He earned a B.E.E. degree from Cornell University and a M.S.E.E. degree from the University of Hawaii. He has been the principal investigator on contracts developing the Infrared Spectral Imaging Radiometer, the Thermal Imaging Radiometer, the NASA Cloud Top Radiometer and Earth Radiation Array, and Hi-Camp II. Previously he was a Senior Systems Engineer for Hughes Aircraft Company where he was systems engineer for the design of the Landsat Thematic Mapper. He received a DARPA Strategic Technology Office Special Award in 1987. 